\title{
Acetaminophen Overdose Enhances Early Cholangiocarcinoma in Opisthorchiasis Hamsters
}

\author{
Pranee Sriraj ${ }^{1,2}$, Thidarut Boonmars ${ }^{2,3,4 *}$, Ratchadawan Aukkanimart ${ }^{1,2}$, Atchara \\ Artchayasawat $^{3,4}$, Glenn N Borlace ${ }^{5}$, Panaratana Ratanasuwan ${ }^{6}$, Benjamabhorn \\ Pumhirunroj $^{7}$
}

\begin{abstract}
Opisthorchiasis which exerted by infection of Opisthorchis viverrini is strongly related to the incident of cholangiocarcinoma (CCA) in many Southeast Asian countries northeastern of Thailand. The O. viverrini infection is primarily caused by raw fish consumption, and repeated exposure to liver fluke. Meanwhile, acetaminophen is usually medicated to relieve pain in particularly people in northeast Thailand. Objective: This study therefore aimed at investigating effects of acetaminophen on pathogenesis in hamsters for opisthorchiasis. Methods: There were 4 groups of hamsters: i) uninfected hamster $(\mathrm{N})$; ii) sole acetaminophen administration $(\mathrm{N}-\mathrm{Ac})$; iii) sole $O$. viverrini infection $(\mathrm{OV})$; and iv) combination of $O$. viverrini infection and acetaminophen (OV-Ac) on pathology of hamsters for 1 month post infection. For analysis of histopathological changes through hematoxylin and eosin, Sirius red and immunohistostaining for Cytokeratin 19 (CK-19), Proliferating cell nuclear antigen (PCNA) and CA 19-9, serum's hamsters were used detected for liver function tests and tumor-related genes expression. Results: After 1 month under these treatments, the OV-Ac showed significantly higher CCA risk, including inflammatory cells were aggregations around bile duct, new bile duct and fibrosis in subcapsular hepatic tissues, than other treatments. These pathological parameters were positively correlated with immunohistochemical staining derived from CK-19, PCNA and CA 19-9. In addition, OV-Ac had significantly higher liver function tests (ALT). Conclusion: Combined intake of liver flukecontaminated raw fishes and acetaminophen rendered more severity of CCA than sole consumption of the contaminated raw fishes.
\end{abstract}

Keywords: Acetaminophen- cholangiocarcinoma- animal model- Opisthorchiasis

Asian Pac J Cancer Prev, 22 (12), 3903-3912

\section{Introduction}

Opisthorchiasis, which is caused by Opisthorchis viverrini infection, is a major public health problem in many Southeast Asian countries, in particular in the northeastern region of Thailand (Sithithaworn and Haswell-Elkins, 2003; Conlan et al., 2011; IARC, 2011). Opisthorchiasis induced hepatobiliary disease is associated with chronic inflammation, (Bility and Sripa, 2014; Sergei et al., 2010) and is an important determinant for the development of cholangiocarcinoma (CCA), or bile duct cancer (IARC, 2011). Exogenous nitrosamine from fermented foods, and drinking alcohol are associated with increased CCA development by increasing inflammation (Honjo et al., 2005; Juasook et al., 2012; Juasook et al.,
2013; Sriraj et al., 2013a; Sriraj et al., 2013b).

Acetaminophen is an antipyretic and analgesic commonly used to treat pain of mild to moderate severity, but it has few anti-inflammatory properties (Sumioka et al., 2004; Goldstein et al., 2005; Liccardi et al., 2005; Saito et al., 2005). Although acetaminophen is safe at therapeutic doses (1-4 g/day), hepatotoxicity can occur with misuse and overdose. Acetaminophen is a major cause of acute liver failure in adults in the United States and many other countries worldwide (Clark, 2001; Brok et al., 2002; Ostapowicz et al., 2002; Lee, 2004; Sumioka et al., 2004; Cooper et al., 2009; Nam et al., 2009; Agarwal et al., 2011) and acute acetaminophen overdose has been shown to lead to hepatic and renal necrosis in humans and experimental animals (Hinson et al., 1981; Harman

${ }^{1}$ Department of Traditional Medicine, Faculty of Natural Resources, Rajamangala University of Technology ISAN Sakon Nakhon Campus, Sakon Nakhon 47160, Thailand. ${ }^{2}$ Neglected, Zoonosis and Vector Borne Disease Research Group, Khon Kaen University, Khon Kaen 40002, Thailand. ${ }^{3}$ Cholangiocarcinoma Research institute, Khon Kaen University,Khon Kaen 40002, Thailand. ${ }^{4}$ Department of Parasitology, Faculty of Medicine, Khon Kaen University, Khon Kaen 40002, Thailand. ${ }^{5}$ Faculty of Pharmaceutical Sciences, Khon Kaen University, Khon Kaen 40002, Thailand. ${ }^{6}$ Department of Anesthesiology, Faculty of Medicine, Khon Kaen University, Khon Kaen, 40002, Thailand. 'Program in Animal Science, Faculty of Agricultural Technology, Sakon Nakhon Rajabhat University, Sakon Nakhon, 47000, Thailand.*For Correspondence: bthida@kku.ac.th 
and Fischer, 1983; Rosen et al., 1983; Sasaki et al., 1983; Savides and Oehme, 1983; Miller and Jollow, 1984; Lupo et al., 1987; Miller and Jollow, 1987; Madhu et al., 1989; Knight et al., 2001; Lee et al., 2004) and has been shown to increase/induce inflammation in humans/animal/in vitro.

Since $O$. viverrini infection and acetaminophen overdose can both cause inflammation and liver injury independently, we hypothesized that $O$. viverrini infection combined with acetaminophen overdose may affect CCA development. The objective of this study was to evaluate the influence of acetaminophen overdose on inflammation and tumor-related gene expression in a Syrian hamster opisthorchiasis model.

\section{Materials and Methods}

\section{Animals and experimental design}

Twenty male Syrian hamsters from the animal unit, Faculty of Medicine, Khon Kaen University were used in this study. Hamsters aged 6 to 8 weeks and weighing 100 grams were kept in a standard environment with a 12-hour alternate light-dark cycle, room temperature 20 to $24^{\circ} \mathrm{C}$ and ambient humidity $60 \pm 10 \%$. There were four experimental groups: i) normal (uninfected) control (N); ii) uninfected with acetaminophen $(\mathrm{N}-\mathrm{Ac})$; iii) $O$. viverrini infected (OV); and iv) combination of $O$. viverrini and acetaminophen (OV-Ac). Pathology parameters were determined one month after infection.

Preparation of Opisthorchis viverrini metacercariae and animal infection

Cyprinoid fishes were collected from an area endemic for opisthorchiasis in Laos PDR. These fishes were crushed using an electric blender and then digested with $0.25 \%$ pepsin- $\mathrm{HCl}$ solution. The mixture was incubated at $37^{\circ} \mathrm{C}$ on a shaking water bath for 1 hour and filtered through a set of sieves possessing pore sizes of 1,000 , 300 , and $106 \mu \mathrm{m}$. The samples were left to settle in a $0.85 \% \mathrm{NaCl}$ solution until the supernatant was clear. $O$. viverrini metacercariae that were $100-150 \mu \mathrm{m}$ in length and showing an obvious black bladder and oral and ventral suckers were selected. Hamsters were infected with 50 active metacercariae each using intragastric intubation.

\section{Acetaminophen preparation}

Acetaminophen tablets $(500 \mathrm{mg}$, Tylenol, Johnson and Johnson, USA) were crushed and dissolved in distilled water. Acetaminophen solution ( $3 \mathrm{mg} / \mathrm{kg} / \mathrm{day})$ was administrated orally to N-Ac and OV-Ac hamsters.

\section{Histopathology}

Livers of the treated hamsters were collected and preserved in a $10 \%$ formalin solution. The preserved livers were serially dehydrated in ethanol $(70 \%, 90 \%$, and $100 \%)$, mounted in paraffin wax and sectioned $(4 \mu \mathrm{m})$ under a microtome. Paraffin wax was removed from the liver sections with absolute xylene. Liver sections were rehydrated with graded concentrations of ethanol (reverse of dehydration) before hematoxylin and eosin staining. In order to detect liver fibrosis, liver sections were dyed with $0.1 \%$ Sirius red (Sigma-Aldrich, St. Louis, USA) for $1 \mathrm{~h}$, washed with $1 \%(\mathrm{v} / \mathrm{v})$ acetic acid, and serially dehydrated in ethanol again. Liver sections were photographed at 10x magnification on a light microscope (Olympus BX51; Tokyo, Japan). Histopathology scores of inflammation and fibrosis were graded by the method modified from Ishak et al., (1995).

\section{Immunohistochemistry (IHC)}

For the immunohistochemical determination of PCNA, CK-19 and CA 19-9 expression, paraffin was removed from liver sections with absolute xylene prior to serial rehydration in $95 \%, 80 \%$ and $70 \%$ ethanol. Antigens were retrieved using $10 \mathrm{mM}$ citrate buffer ( $\mathrm{pH}$ 6.0) under autoclave conditions of $121^{\circ} \mathrm{C}$ for 5 minutes. Subsequently, the sections were cleaned by soaking in washing solution $(0.05 \%$ Tween $20+$ PBS $)$ for 10 minutes. Endogenous peroxidase in the samples was inactivated using a mixture of $3 \% \mathrm{H}_{2} \mathrm{O}_{2}$ and methyl alcohol. The liver sections were washed again in a mixture of $0.05 \%$ tween 20 and PBS. Non-specific antigens in liver tissues were blocked by using 5\% skim milk. Samples were incubated with PCNA monoclonal antibody (1:50 dilution, Novocastra, UK), CK-19 rabbit polyclonal antibody (1:50 dilution, Abcam, UK), or CA19-9 rabbit polyclonal antibody (1:200 dilution, Abcam, USA) at $37^{\circ} \mathrm{C}$ for 1 hour before washing with a mixture of $0.05 \%$ Tween 20 and PBS. Envision-system-HRP labelled Polymer anti-rabbit and anti-mouse antibodies (Dako, USA) were added as secondary antibodies. A chromogen solution of AEC and peroxidase was added for color development. All sample sections were counterstained with hematoxylin and mounted. Positive immune reactions of PCNA, CK-19, and CA19-9 were visualized as red color. PCNA expression was found in the nucleus of active cells, CK-19 was expressed in the cytoplasm of developing biliary trees, and CA19-9 was expressed in the nucleus of tumor cells.

The degree of immunohistochemical staining was evaluated by semi-quantifying the percentage of immunopositivity. Scoring was as follows: $0=$ negative or $<10 \%$ area stained, $1=10-25 \%$ area stained, $2=25-50 \%$ area stained, $3=50-75 \%$ area stained, and $4=>75 \%$ area stained (modified from Muerkoster et al. 2004).

\section{Liver injury study}

Enzymatic method (modified from Sriraj et al., 2016) was employed to determine effect of acetaminophen on liver responses. Serum alanine aminotransferase (ALT) activity and alkaline phosphatase (ALP) are a sensitive marker of liver tissue injury. Whole blood was drawn from the heart into $1.5 \mathrm{ml}$ tube. Whole blood was centrifuged at $9,100 \mathrm{~g}$ at $4^{\circ} \mathrm{C}$ for $10 \mathrm{~min}$ to separate the serum from packed red cells and keep at $-20^{\circ} \mathrm{C}$ until it was used. The serum ALT and ALP was performed on a spectrophotometer (Automate RA 100).

\section{Expression of tumor-related gene study using Real time RT-PCR technique \\ Total RNA extraction}

The RNA extraction was performed following the method of Boonmars et al., (2010). In brief, three hundred milligram liver samples derived from hilar's region 
were mixed with $3 \mathrm{ml}$ of Trizol ${ }^{\circledR}$ solution (Invitrogen, USA), and homogenized in a glass homogenizer. The homogenized liver samples were centrifuged at 13,000 $\mathrm{g}$ at $4^{\circ} \mathrm{C}$. Chloroform was added to samples for RNA separation, and isopropanol was subsequently added for precipitation of RNA. RNA pellets were washed with $75 \%$ ethanol, and then dissolved in RNase free water. Finally, concentrations and purity of total RNA was determined on a spectrophotometer at the wavelengths of $260 \mathrm{~nm}$ and $280 \mathrm{~nm}$.

\section{Complementary DNA preparation}

Oligo (dT)15 primers and M-MLV master mix (5x reaction buffer, 20 units RNase inhibitor, $10 \mathrm{mM}$ dNTP mix, 200 units M-MLV Reverse transcriptase) (Invitrogen, USA) were added to the purified RNA to prepare RNA templates for producing complementary DNA (cDNA). The suspensions were then mixed thoroughly on a vortex mixer and incubated at $42^{\circ} \mathrm{C}$ for 1 hour. The sample mixtures were then incubated at $70^{\circ} \mathrm{C}$ for 10 minutes, and finally chilled on ice to stop any biochemical reactions and the cDNA was stored at $-20^{\circ} \mathrm{C}$. Validation of cDNA templates was determined by visualization of a $228 \mathrm{bp}$ product using G3PDH primers.

\section{Relative real time $R T-P C R$}

Primers of tumor relevant genes pertaining to CCA employed for quantitative RT-PCR analysis included: G3PDH (housekeeping gene), p53, BAX,CK-19, $T G F-\beta, I L-6$. The $G 3 P D H$ gene contained forward 5'-GGCATTGTGGAAGGGCTCAT-3', and reverse 5'-GACACATTGGGGGTAGGAACAC-3'. The $p 53$ gene had forward 5'-AAGGCGATAGTTTGGCTCCT-3', and reverse 5'-CTGGGGTCTTCCAGTGTGAT-3'. The $B A X$ gene had forward 5'-AGCTGCAGAGGATGATTGCT-3', and reverse 5'- CTCTCGGAGGAAGTCCAGTG-3' (Boonmars et al., 2008). The $C K-19$ gene possessed forward 5'-GCGGGACAAGATTCTTGGTG-3', and reverse 5'-CTTCAGGCCTTCGATCTGCAT-3' (Juasook et al., 2013). The $T G F-\beta$ gene had forward 5'-GCTGGAAGTGGATTCACGA-3', and reverse
Acetaminophen Overdose Enhances Early Cholangiocarcinoma

5'-CTTGCGACCCACGTAGTACA-3' (Boonjaraspinyo et al., 2011). Meanwhile, the $I L-6$ gene contained forward 5'-CCAGATCTACCTGGAGTTTG-3', and reverse 5'-CCACTCCTTTTGTGACTCC-3' (Juasook et al., 2013).

Quantitative real-time PCR was conducted on the LightCycler $^{\circledR} 480$ System (Idaho Technology, Inc., UT, USA). Reaction mixture was composed of $2 \mu \mathrm{l}$ cDNA template, $10 \mu \mathrm{S} \mathrm{SYBR}{ }^{\circledR}$ Premix Ex Taq II (Tli RNaseH Plus; Takara, Japan), $0.8 \mu \mathrm{l}$ of $10 \mu \mathrm{M}$ forward and reverse primers, and $6.4 \mu \mathrm{l}$ sterile distilled water. Real-time PCR conditions employed in this study were performed following our previous study (Sriraj et al., 2016) as shown in Table 1. All data of gene expressions were normalized with the housekeeping gene $(G 3 P D H)$ and expressed as relative levels of gene expression.

\section{Statistical analysis}

One way analysis of variance was used to determine effects of acetaminophen, O. viverrini, and their combination on liver function tests and gene expression level. Chi-square was used to determine semi-qualitative IHC and histopathological changes. All data analyses were performed by SPSS version 16.0 (IBM, USA). The significant differences were at $\mathrm{p}<0.05$.

\section{Results}

\section{Histopathological responses}

The non-infected control group $(\mathrm{N})$ showed normal liver morphology as indicated by the small size of the hepatic bile duct, normal hepatocyte architecture and absence of any inflammatory aggregates (Figure 1a, b). Inflammatory aggregates were found in hepatic tissue of the non-infected acetaminophen control (N-Ac) group, while the $O$. viverrini infected $(\mathrm{OV})$ and $O$. viverrini infected acetaminophen (OV-Ac) groups showed inflammatory aggregates surrounding the hepatic bile duct and in the hilar region as well as in hepatic tissue.

However, in N-Ac group, low level of the aggregation of inflammatory cells was found surrounding bile ducts
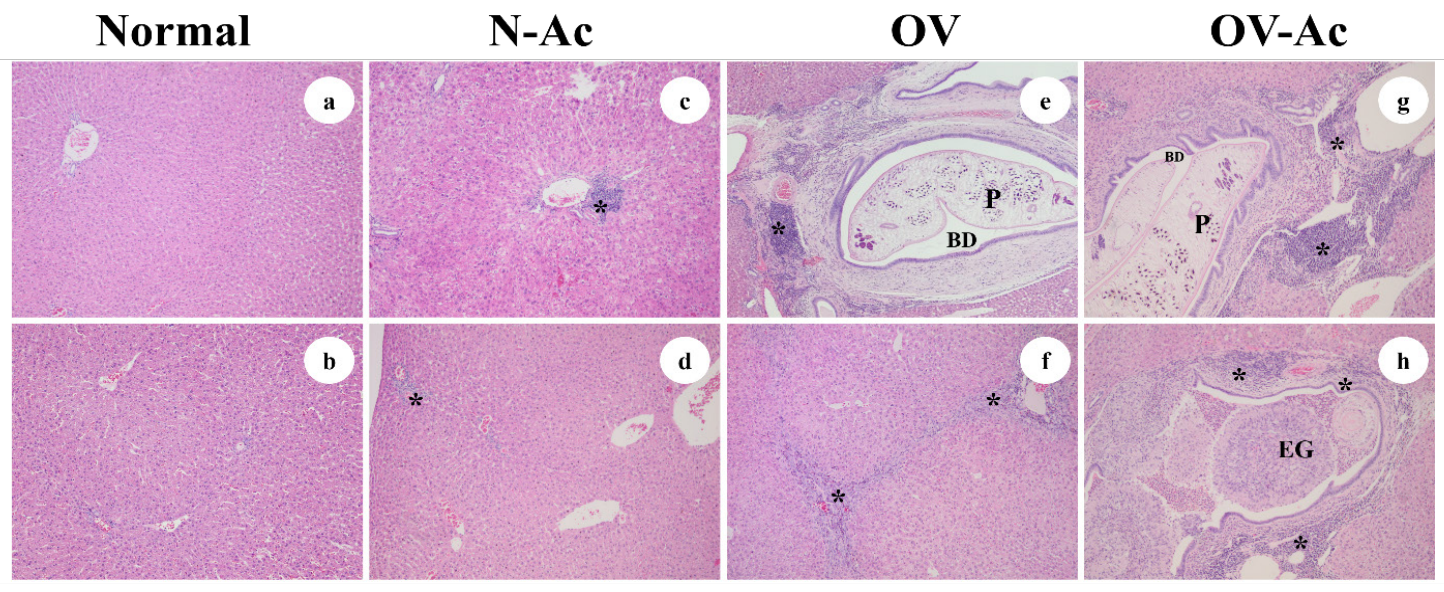

Figure 1. Representative Histopathological Changes in the Hepatobiliary System of the Experimental Groups; Normal; normal hamster $(\mathrm{a}, \mathrm{b}), \mathrm{N}-\mathrm{Ac}$; normal hamster treated with acetaminophen $(3 \mathrm{mg} / \mathrm{kg} / \mathrm{d})(\mathrm{c}, \mathrm{d}), \mathrm{OV}$; hamster infected with O. viverrini (e, f), OV-Ac; hamster infected with O. viverrini and treated with acetaminophen $(3 \mathrm{mg} / \mathrm{kg} / \mathrm{d})(\mathrm{g}, \mathrm{h})$. P; Parasite in the intrahepatic bile duct (BD), *; inflammatory cells. 
Table 1. Conditions of Real Time RT-PCR.

\begin{tabular}{llc}
\hline Gene & Real time RT-PCR condition & Cycles \\
\hline$G 3 P D H$ & $95^{\circ} \mathrm{C}$ for $15 \mathrm{~s}, 60^{\circ} \mathrm{C}$ for $60 \mathrm{~s}, 72{ }^{\circ} \mathrm{C}$ for $60 \mathrm{~s}$ & 35 \\
$p 53, B A X, T G F-\beta, C K 19$ & $95^{\circ} \mathrm{C}$ for $15 \mathrm{~s}, 62^{\circ} \mathrm{C}$ for $60 \mathrm{~s}, 72{ }^{\circ} \mathrm{C}$ for $60 \mathrm{~s}$ & 40 \\
$I L-6$ & $95^{\circ} \mathrm{C}$ for $15 \mathrm{~s}, 64^{\circ} \mathrm{C}$ for $60 \mathrm{~s}, 72{ }^{\circ} \mathrm{C}$ for $60 \mathrm{~s}$ & 40 \\
\hline
\end{tabular}

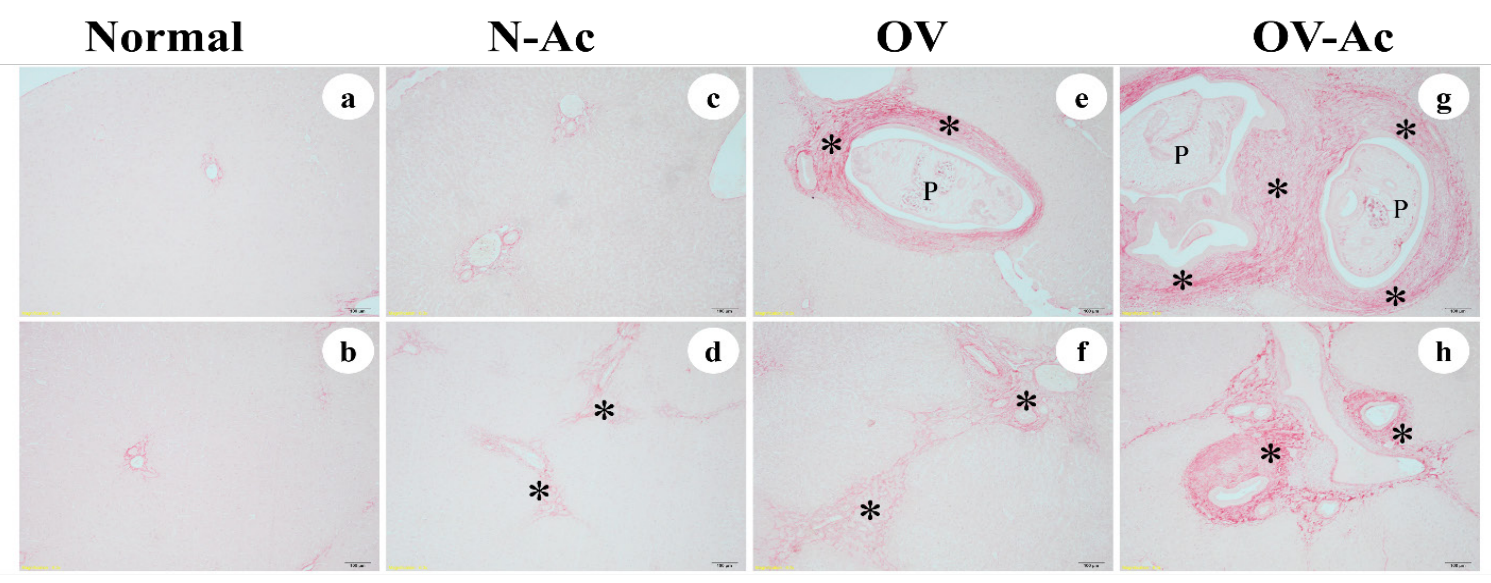

Figure 2. Sirius Red Staining of Fibrosis Formation in Liver Tissue of Experimental Groups; Normal; normal hamster (a, b), N-Ac; normal hamster treated with acetaminophen $(3 \mathrm{mg} / \mathrm{kg} / \mathrm{d})(\mathrm{c}, \mathrm{d}), \mathrm{OV}$; hamster infected with $O$. viverrini $(\mathrm{e}, \mathrm{f}), \mathrm{OV}-\mathrm{Ac}$; hamster infected with $O$. viverrini and treated with acetaminophen $(3 \mathrm{mg} / \mathrm{kg} / \mathrm{d})(\mathrm{g}, \mathrm{h})$. P; Parasite in the intrahepatic bile duct, *; fibrosis. The positive staining of collagen substance was evident red color and the degree of fibrosis in each group was determined under light microscope and graded the pathology using the histopathological grading criteria.

(Figure 1c) and hepatic tissues (Figure 1d). Whereas high levels of the inflammatory cell aggregates were shown in OV (Figure 1e and $\mathrm{f}$ ) and OV-Ac (Figure $1 \mathrm{~g}$ and $\mathrm{h}$ ) groups. In addition, the inflammatory levels were significantly higher in OV-Ac than N-Ac and OV groups. It was also found that new bile duct proliferation was the highest in OV-Ac (Table 2 and Figure 1)

Liver fibrosis was found in all treatments, nevertheless they were different levels. In the $\mathrm{N}$ group, little fibrosis at the bile ducts of the portal triad was observed (Figure $2 \mathrm{a}$ and $\mathrm{b}$ ). Meanwhile in N-Ac group, occurrence of little fibrosis was seen on the bile ducts of the portal triad (Figure 2c) and sub-scapular area (Figure 2d). Whereas in OV and OV-Ac groups, high level of the fibrosis was observed. Higher levels of the fibrosis were found in $\mathrm{OV}$-Ac group (Figure $2 \mathrm{~g}$ and $\mathrm{h}$ ) than OV group (Figure $2 \mathrm{e}$ and $\mathrm{f})$.

\section{Liver function test}

ALT level in the OV-Ac group was highest and significantly increased compared with OV group ( $p$ $<0.05$ ), as shown in Figure 6. The serum alanine transaminase (ALT) level was correlated with the histopathological changes (liver damaged).

\section{Immunohistochemistry}

Semi-quantitative IHC scores were analysed. OV-Ac group were compared with OV group. The PCNA antigen,
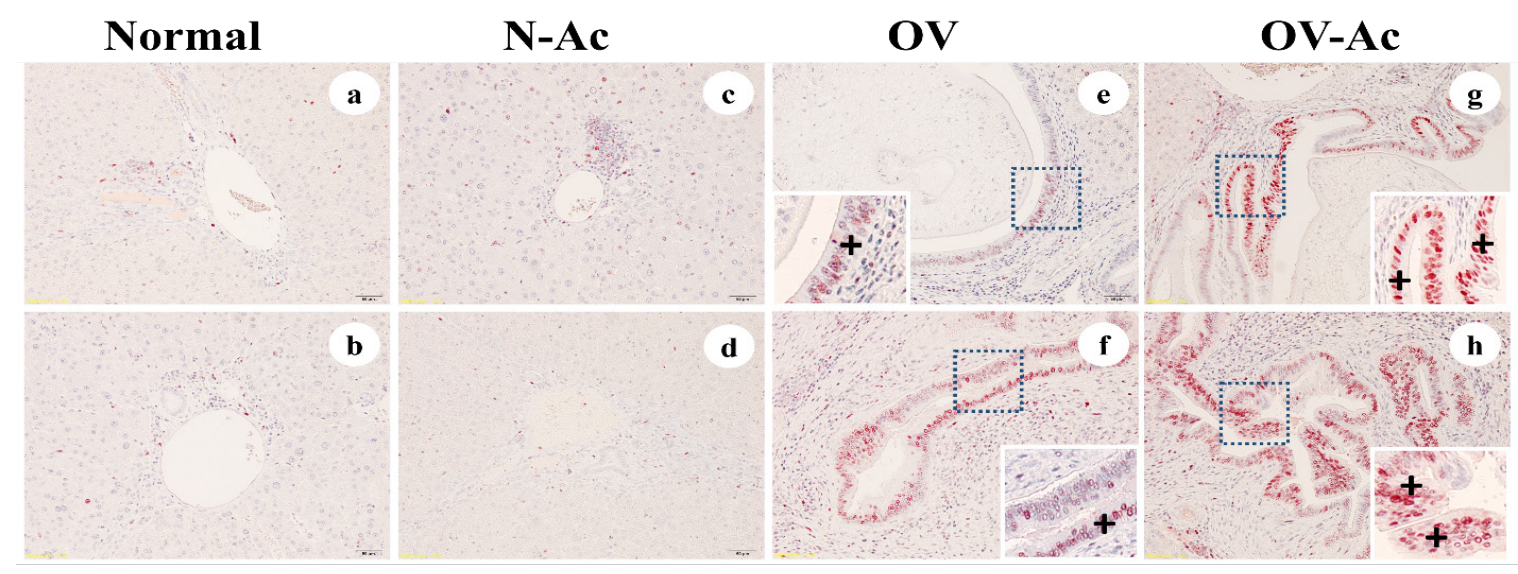

Figure 3. Representative the Expression of PCNA in the Liver Tissue of the Experimental Groups; Normal; normal hamster (a, b), N-Ac; normal hamster treated with acetaminophen $(3 \mathrm{mg} / \mathrm{kg} / \mathrm{d})(\mathrm{c}, \mathrm{d}), \mathrm{OV}$; hamster infected with $O$. viverrini (e, f), OV-Ac; hamster infected with $O$. viverrini and treated with acetaminophen $(3 \mathrm{mg} / \mathrm{kg} / \mathrm{d})(\mathrm{g}, \mathrm{h}) .+$; positive area of PCNA was shown red color in nuclei of cells. 


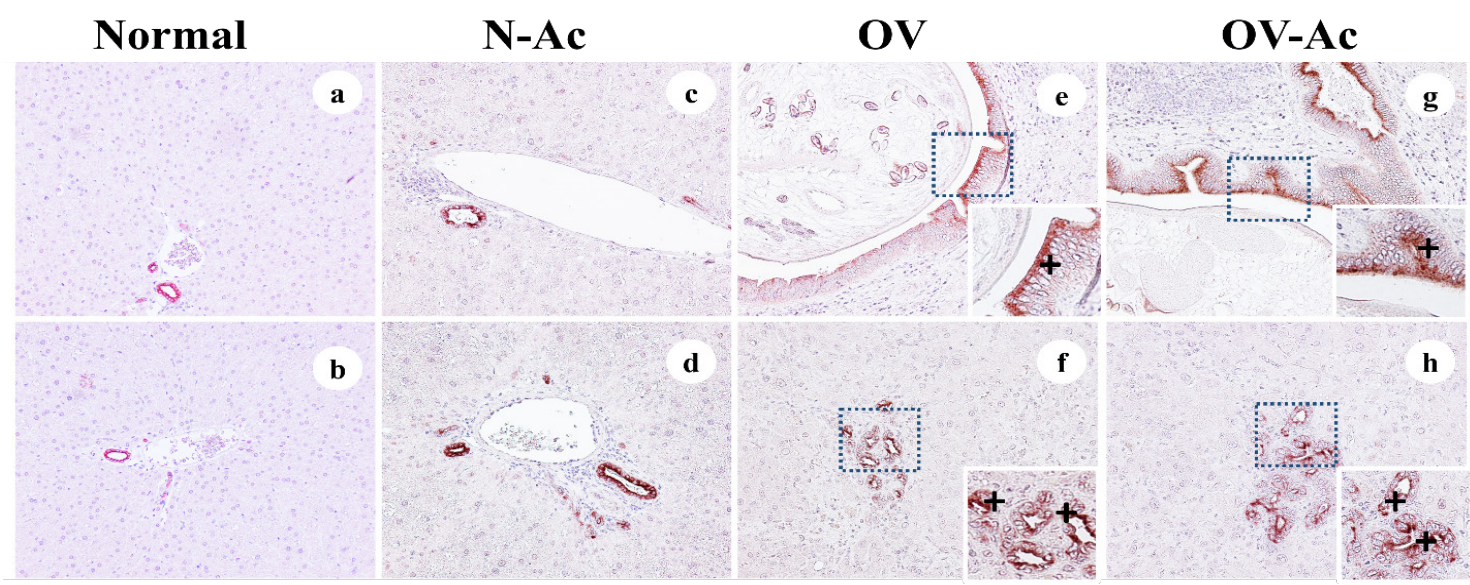

Figure 4. Representative the Expression of CK-19 in the Liver Tissue of the Experimental Groups; Normal; normal hamster $(\mathrm{a}, \mathrm{b}), \mathrm{N}-\mathrm{Ac}$; normal hamster treated with acetaminophen $(3 \mathrm{mg} / \mathrm{kg} / \mathrm{d})(\mathrm{c}, \mathrm{d}), \mathrm{OV}$; hamster infected with $O$. viverrini (e, f), OV-Ac; hamster infected with $O$. viverrini and treated with acetaminophen $(3 \mathrm{mg} / \mathrm{kg} / \mathrm{d})(\mathrm{g}, \mathrm{h})$. + ; positive area of CK-19 was shown red color in cytoplasm.

generally expression in the nuclei of cells during DNA synthesis phase of the cell cycle and had been used to locate the active bile duct cell proliferation in the liver tissue. In normal condition, the positive area of PCNA was not found in the nucleus of bile duct epithelial cells as shown in this study, in normal control $(\mathrm{N})$ group and $\mathrm{N}-\mathrm{Ac}$ group were not observed the expression of PCNA. In all $O$. viverrini infection groups (OV and OV-Ac) had shown PCNA positive area in nuclei of bile duct epithelial cells, though OV-Ac group found strongly positive more than OV group (Figure 3 and Table 3).
The expression of CK-19 had been used for pathological diagnosis mainly to confirm the epithelial cancer cell origin as the epithelial tumor marker. The positive area of CK-19 found in the cytoplasm of bile duct epithelial cells in the liver tissue of all experimental groups but difference degree. CK-19 was strongly expressed in the OV-Ac corresponding to PCNA staining (Figure 4 and Table 3).

The CA19-9 is a protein that is found in cancer cells. The positive area of CA19-9 found in the nucleus of cancer cells, which found in only OV-Ac group (Figure 5 and Table 3).

Table 2. Histopathological Features of Liver Grading Criteria at 1 Month Post Infection by Microscopic Examination.

\begin{tabular}{|c|c|c|c|c|c|}
\hline \multirow[t]{2}{*}{ Histopathological features } & \multirow[t]{2}{*}{ Score } & \multicolumn{4}{|c|}{ Groups of experiment } \\
\hline & & $\begin{array}{c}\mathrm{N} \\
\mathrm{N}=5 \\
\mathrm{~N}(\%)\end{array}$ & $\begin{array}{c}N-A c \\
N=5 \\
N(\%)\end{array}$ & $\begin{array}{c}\mathrm{OV} \\
\mathrm{N}=5 \\
\mathrm{~N}(\%) \\
\end{array}$ & $\begin{array}{c}\text { OV-Ac } \\
\mathrm{N}=5 \\
\mathrm{~N}(\%)\end{array}$ \\
\hline \multicolumn{6}{|l|}{ Inflammation } \\
\hline \multirow[t]{5}{*}{ Periportal inflammation } & 0 & $5(100)$ & $2(40)$ & & \\
\hline & 1 & & $3(60)^{\mathrm{a}}$ & & \\
\hline & 2 & & & $5(100)$ & \\
\hline & 3 & & & & $3(60)$ \\
\hline & 4 & & & & $2(40)^{b}$ \\
\hline \multirow[t]{5}{*}{ Focal inflammation } & 0 & $5(100)$ & $2(40)$ & & \\
\hline & 1 & & $3(60)^{\mathrm{a}}$ & & \\
\hline & 2 & & & $3(60)$ & \\
\hline & 3 & & & $2(40)$ & $1(20)$ \\
\hline & 4 & & & & $4(80)^{b}$ \\
\hline \multirow[t]{7}{*}{ Fibrosis } & 0 & $5(100)$ & $5(100)$ & & \\
\hline & 1 & & & & \\
\hline & 2 & & & $3(60)$ & \\
\hline & 3 & & & $2(40)$ & \\
\hline & 4 & & & & $2(40)$ \\
\hline & 5 & & & & $3(60)^{b}$ \\
\hline & 6 & & & & \\
\hline
\end{tabular}

$\mathrm{N}$, number of hamster; $\mathrm{a}, \mathrm{P}<0.05$ compared with $\mathrm{N}$ group; $\mathrm{b}, \mathrm{P}<0.05$ compared with $\mathrm{OV}$ group. 


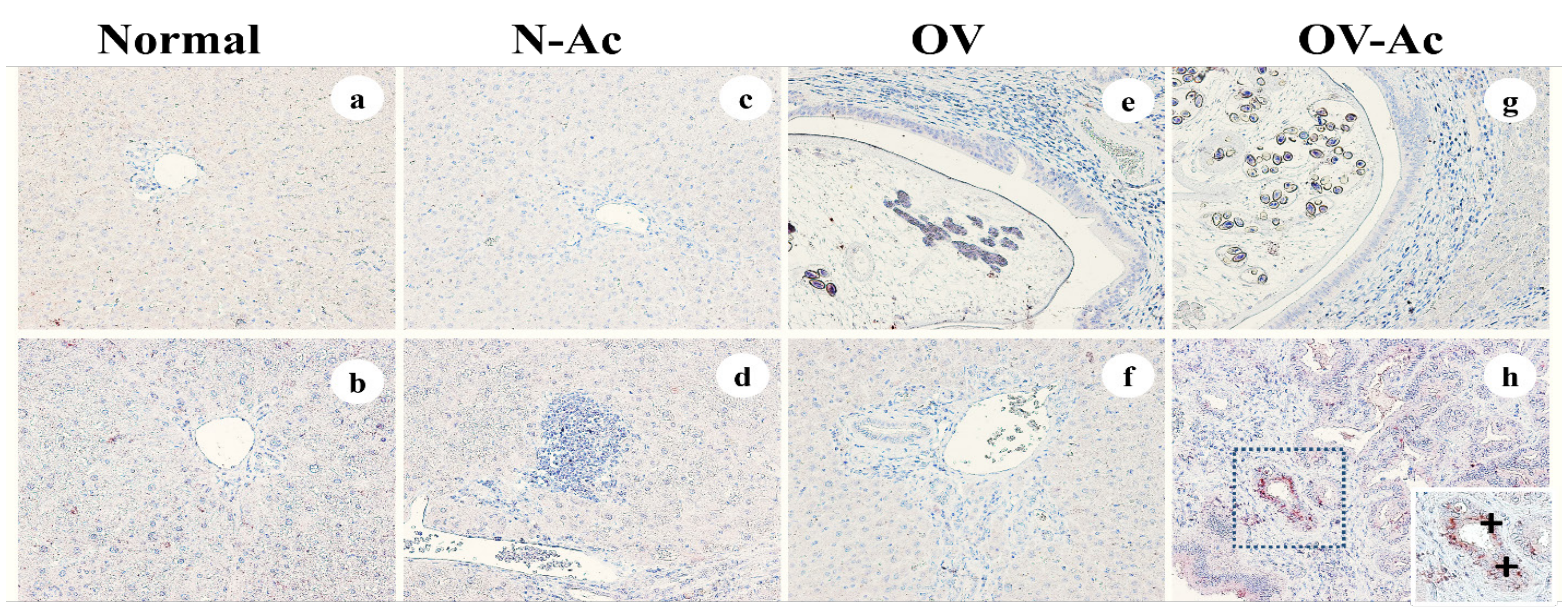

Figure 5. Representative the Expression of CA19-9 in the Liver Tissue of the Experimental Groups; Normal; normal hamster (a, b), N-Ac; normal hamster treated with acetaminophen $(3 \mathrm{mg} / \mathrm{kg} / \mathrm{d})(\mathrm{c}, \mathrm{d}), \mathrm{OV}$; hamster infected with $O$. viverrini $(\mathrm{e}, \mathrm{f}), \mathrm{OV}-\mathrm{Ac}$; hamster infected with $O$. viverrini and treated with acetaminophen $(3 \mathrm{mg} / \mathrm{kg} / \mathrm{d})$ $(\mathrm{g}, \mathrm{h}) .+$; positive area of CA19-9 was shown red color in nuclei of cancer cell.

\section{The expression of tumor relevant genes}

The expression level of apoptotic genes ( $B A X$, p53), inflammatory genes (TGF and ILG) and CK-19 epithelial tumor marker gene relative to the expression of housekeeping gene (G3PDH) in OV and OV-Ac compared to normal control group (N) and representative as fold change.

The expression level of apoptotic genes ( $B A X$, $p 53$ and $T G F-\beta$ ), inflammatory genes and tumor marker genes (CK-19 and IL-6) in OV-Ac groups were significantly increased compared with OV group $(\mathrm{p}<0.05)$ as shown in Figure 7 . These results were correlated with histopathological changed, fibrogenesis and immunostaining.

\section{Discussion}

Acetaminophen is the most used drug world-wide. At therapeutic doses $(4 \mathrm{~g} / \mathrm{d})$, it is safe and effective. However severe liver injury, liver failure and even death can occur with misuse and overdose. (Davidson and Eastham, 1966; Gow et al., 1997; Bernal et al., 1998a; Bernal et al., 1998b; Makin et al., 1998; Gow et al., 1999; Larson et al., 2006; Sood et al., 2013) and animal models (Banda and Quart, 1987; Dalhoff et al., 1991; Knight et al., 2003; James et al., 2004; LoGuidice and Boelsterli, 2011; Yang et al., 2012; Bhushan et al., 2013). Acetaminophen metabolism by cytochrome P450 2E1 to hepatotoxic N-acetyl-pbenzoquinoneimine (NAPQI) which depletes glutathione (GSH) induces oxidative stress lipid peroxidation (LPO) mitochondrial dysfunction and DNA fragmentation which results in hepatocyte necrosis, liver damage and death (Nelson, 1990; Rashed et al., 1990; Tirmenstein and Nelson, 1990; Cohen and Khairallah, 1997; James et al., 2001a; James et al., 2001b; James et al., 2003a; James et al., 2003b).

The effects of acetaminophen on Syrian hamster opisthorchiasis and related hepatic bile duct disease has not been previously investigated. In this study we found that acetaminophen overdose induced liver damage

Table 3. Effect of Acetaminophen on IHC Scores for the Expression of CK19, PCNA, and CA19-9 in Liver Tissue

\begin{tabular}{|c|c|c|c|c|c|c|c|c|}
\hline \multirow[t]{2}{*}{ Antigen } & \multirow[t]{2}{*}{ Groups } & \multicolumn{5}{|c|}{ IHC score } & \multirow{2}{*}{$\begin{array}{c}\text { Total } \\
\text { N }\end{array}$} & \multirow[t]{2}{*}{ P-value } \\
\hline & & $\begin{array}{c}0 \\
\mathrm{~N}(\%)\end{array}$ & $\begin{array}{c}1 \\
\mathrm{~N}(\%)\end{array}$ & $\begin{array}{c}2 \\
\mathrm{~N}(\%)\end{array}$ & $\begin{array}{c}3 \\
\mathrm{~N}(\%)\end{array}$ & $\begin{array}{c}4 \\
\mathrm{~N}(\%)\end{array}$ & & \\
\hline \multirow[t]{4}{*}{ PCNA } & $\mathrm{N}$ & $5(100)$ & & & & & 5 & \\
\hline & $\mathrm{N}-\mathrm{Ac}$ & $5(100)$ & & & & & 5 & \\
\hline & OV & & $3(60)$ & $2(40)$ & & & 5 & \\
\hline & OV-Ac & & & $1(20)$ & $4(80)$ & & 5 & $0.011^{*}$ \\
\hline \multirow[t]{4}{*}{ CK-19 } & $\mathrm{N}$ & $4(80)$ & $1(20)$ & & & & 5 & \\
\hline & $\mathrm{N}-\mathrm{Ac}$ & $3(60)$ & $2(40)$ & & & & 5 & \\
\hline & OV & & $1(20)$ & $2(40)$ & $2(40)$ & & 5 & \\
\hline & OV-Ac & & & & $2(40)$ & $3(60)$ & 5 & $0.026^{*}$ \\
\hline \multirow[t]{4}{*}{ CA19-9 } & $\mathrm{N}$ & $5(100)$ & & & & & 5 & \\
\hline & $\mathrm{N}-\mathrm{Ac}$ & $5(100)$ & & & & & 5 & \\
\hline & $\mathrm{OV}$ & $5(100)$ & & & & & 5 & \\
\hline & OV-Ac & $1(20)$ & $4(80)$ & & & & 5 & $0.003 *$ \\
\hline
\end{tabular}

$\mathrm{N}$, number of hamster; ${ }^{*}, \mathrm{P}<0.05$ compared with OV group 

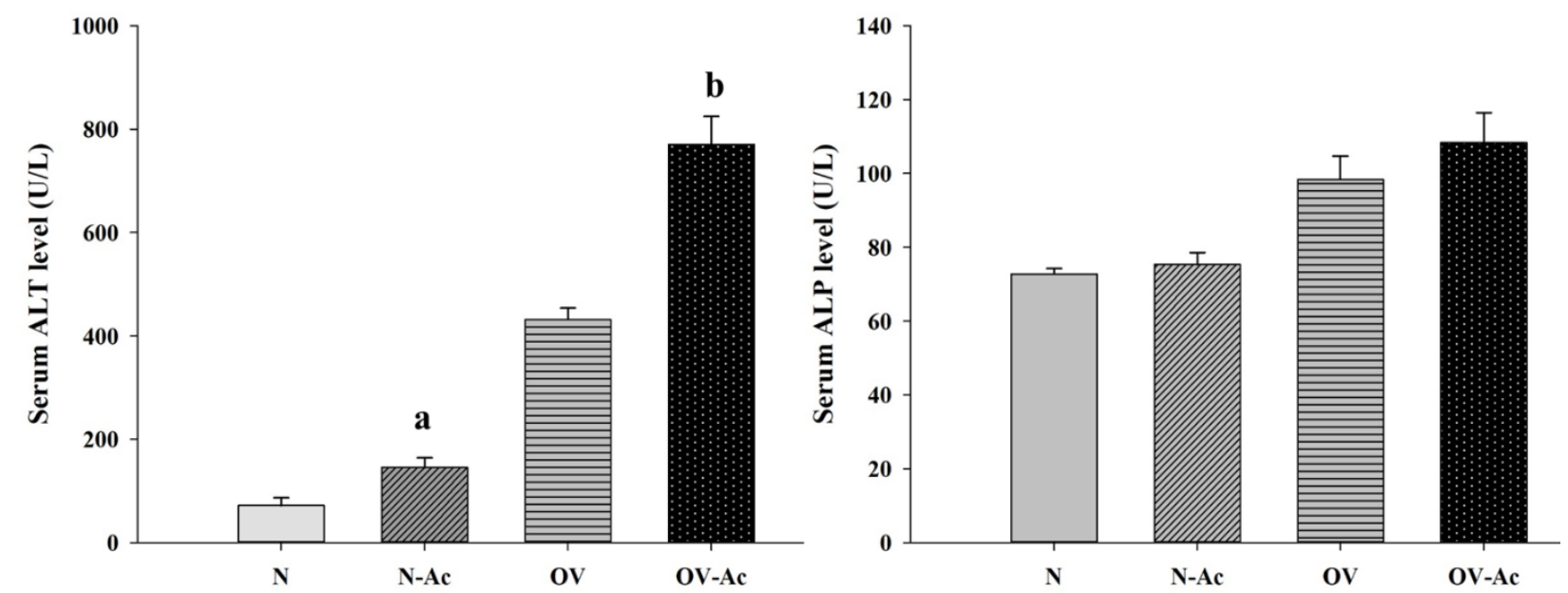

Figure 6. Effects of Acetaminophen on Liver Function Test (ALT and ALP); Normal; normal hamster, N-Ac; normal hamster treated with acetaminophen $(3 \mathrm{mg} / \mathrm{kg} / \mathrm{d}), \mathrm{OV}$; hamster infected with $O$. viverrini, OV-Ac; hamster infected with $O$. viverrini and treated with acetaminophen $(3 \mathrm{mg} / \mathrm{kg} / \mathrm{d})$. a $; \mathrm{P}<0.05$ compared with $\mathrm{N}$ group, b; $\mathrm{P}<0.05$ compared with OV group.

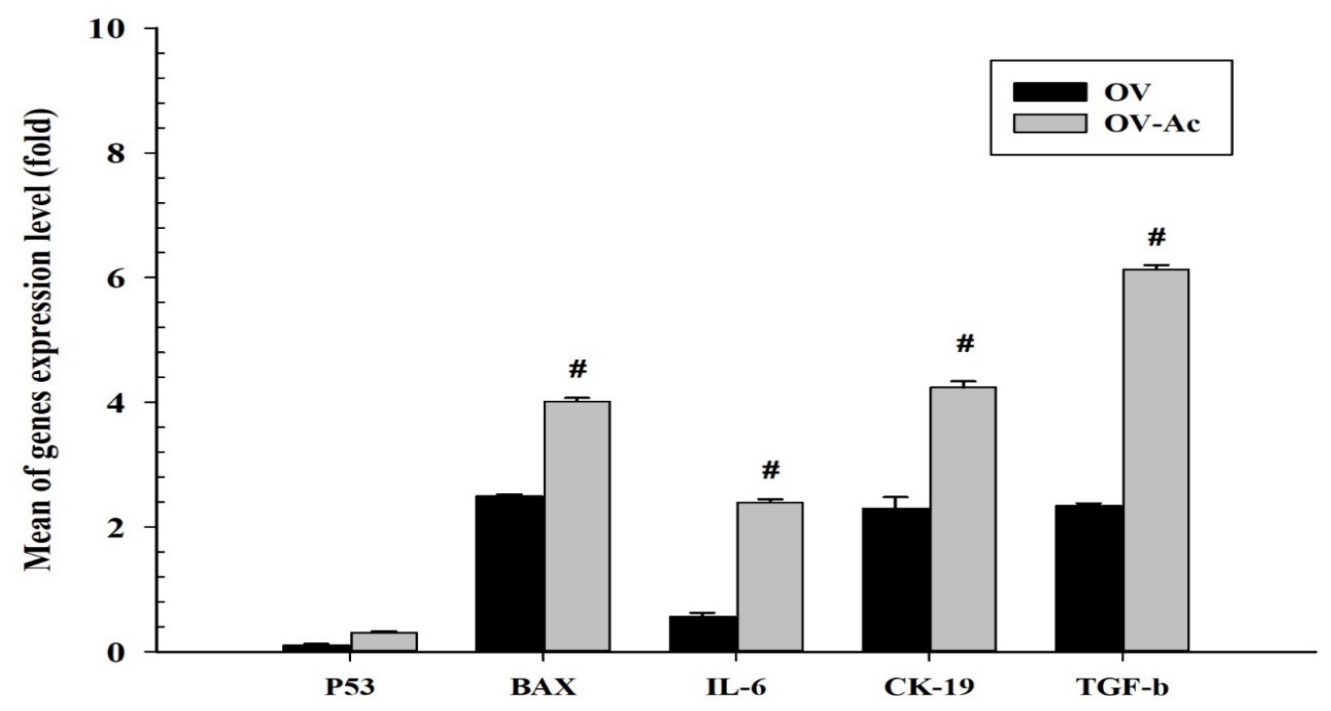

Figure 7. The Expression Profiles of Tumor Relevant Genes ( $p 53, B A X, I L-6, C K-19$ and $T G F-\beta)$ relative to the expression of housekeeping gene (G3PDH) compared to normal control group $(\mathrm{N})$ and representative as fold change. $\mathrm{OV}$, infected with $O$. viverrini alone; OV-Ac; hamster infected with $O$. viverrini and treated with acetaminophen $(3 \mathrm{mg} / \mathrm{kg} / \mathrm{d}) . \#: \mathrm{P}<0.05$.

(liver function test, ALT levels) and fibrogenesis as shown in histopathology study (HandE, Sirius red). Liver pathology was correlated with increased expression of IL-6 and TGF- $\beta$. Importantly, TGF- $\beta$ is also produced by stellate cells in the liver in response to injury creating a self-perpetuating cycle of fibrosis. After tissue injury, inflammatory cells (primarily neutrophils, eosinophils and macrophages) accumulate at tissue damaged sites characterizing/initiating the repair and regenerative phases of the inflammatory response (Widmann and Fahimi, 1975; Klein, 2007; Siracusa et al., 2008; Jenkins et al., 2011). Oxidative stress is involved in hepatotoxicity following acetaminophen overdose, due to the decrease in antioxidant enzymes activities such as glutathione peroxidase and catalas, increasing the effect of reactive oxygen species (ROS) like hydrogen peroxide, superoxide and peroxynitrite (Knight et al., 2001; Chen et al., 2009; Burke et al., 2010; Hinson et al., 2010; Agarwal et al., 2011). Moreover, acetaminophen overdose is a renal and hepatic toxicity effect, which was shown in increases the activities of liver and kidney enzymes (Table 2), these result agreed with previous study (Jeffery and Lafferty, 1981; Rzucidlo et al., 2000; Boutis and Shannon, 2001) in which APAP overdose increases the activities of liver and kidney enzymes in dogs model. Furthermore, these present study showed that APAP induces apoptosis (genes expression) similar to previous study APAP can induces apoptosis in human hepatoblastoma $\mathrm{HuH7}$ cells through mitochondrial cytochrome $\mathrm{c}$ release and caspase activation (El-Hassan et al., 2003; Kass et al., 2003; Kon et al., 2007).

This result suggests that consuming acetaminophen overdose and infection with OV may increase the early 
hepatitis, cholangitis, cholangiofibrosis, and risk of cholangiocarcinoma.

\section{Author Contribution Statement}

Data curation, investigation, methodology and formal analysis; TB, PS, RA, AA, GB, PR and BP. Conceptualization and project administration; TB and PS. Supervision and visualization; TB. Writing-original draft and writing-review and editing; TB, PS and RA.

\section{Acknowledgements}

This research was supported by the Basic Research Fund of Khon Kaen University under the Cholangiocarcinoma Research institute, Faculty of Medicine, Khon Kaen University, Thailand.

\section{Ethical approvals}

All experiments were conducted according to the guidelines of the National Committee of Animal Ethics and the protocol was approved by the Animal Ethics Committee of the Faculty of Medicine, Khon Kaen University, Thailand (AEKKU 47/2556).

\section{Statement of conflict of interest}

No conflict of interest.

\section{References}

Agarwal R, MacMillan-Crow LA, Rafferty TM, et al (2011). Acetaminophen-induced hepatotoxicity in mice occurs with inhibition of activity and nitration of mitochondrial manganese superoxide dismutase. J Pharmacol Exp Ther, 337, 110-6.

Banda PW, Quart BD (1987). The use of N-acetylcysteine long after an acetaminophen overdose in mice. Toxicol Lett, 36, 89-94.

Bernal W, Donaldson P, Underhill J, et al (1998a). Tumor necrosis factor genomic polymorphism and outcome of acetaminophen (paracetamol)-induced acute liver failure. J Hepatol, 29, 53-9.

Bernal W, Wendon J, Rela M, et al (1998b). Use and outcome of liver transplantation in acetaminophen-induced acute liver failure. Hepatology, 27, 1050-5.

Bhushan B, Borude P, Edwards G, et al (2013). Role of bile acids in liver injury and regeneration following acetaminophen overdose. Am J Pathol, 183, 1518-26.

Bility MT, Sripa B (2014). Chronic Opisthorchis viverrini infection and associated hepatobiliary disease is associated with iron loaded M2-like macrophages. Korean J Parasitol, 52, 695-9.

Boonjaraspinyo S, Boonmars T, Aromdee C, Puapairoj A, Wu Z (2011). Indirect effect of a turmeric diet: enhanced bile duct proliferation in Syrian hamsters with a combination of partial obstruction by Opisthorchis viverrini infection and inflammation by N-nitrosodimethylamine administration. Parasitol Res, 108, 7-14.

Boonmars T, Srirach P, Kaewsamut B,et al (2008). Apoptosisrelated gene expression in hamster opisthorchiasis post praziquantel treatment. Parasitol Res, 102, 447-55.

Boutis K, Shannon M (2001). Nephrotoxicity after acute severe acetaminophen poisoning in adolescents. J Toxicol Clin Toxicol, 39, 441-5.
Brok J, Buckley N, Gluud C (2002). Interventions for paracetamol (acetaminophen) overdoses. Cochrane Database Syst Rev, 2, CD003328.

Burke AS, MacMillan-Crow LA, Hinson JA (2010). Reactive nitrogen species in acetaminophen-induced mitochondrial damage and toxicity in mouse hepatocytes. Chem Res Toxicol, 23, 1286-92.

Chen YH, Lin FY, Liu PL, et al (2009). Antioxidative and hepatoprotective effects of magnolol on acetaminopheninduced liver damage in rats. Arch Pharm Res, 32, 221-8.

Clark J (2001). Acetaminophen poisoning and the use of intravenous N-acetylcysteine. Air Med J, 20, 16-7.

Cohen SD, Khairallah EA (1997). Selective protein arylation and acetaminophen-induced hepatotoxicity. Drug Metab Rev, 29, 59-77.

Conlan JV, Sripa B, Attwood S, et al (2011). A review of parasitic zoonoses in a changing Southeast Asia. Vet Parasitol, 182, $22-40$.

Cooper SC, Aldridge RC, Shah T, et al (2009). Outcomes of liver transplantation for paracetamol (acetaminophen)-induced hepatic failure. Liver Transpl, 15, 1351-7.

Dalhoff K, Hansen PB, Ott P, et al (1991). Acute ethanol administration reduces the antidote effect of $\mathrm{N}$-acetylcysteine after acetaminophen overdose in mice. Hum Exp Toxicol, 10, 431-3.

Davidson DG, Eastham WN (1966). Acute liver necrosis following overdose of paracetamol. Br Med J, 2, 497-9.

El-Hassan H, Anwar K, Macanas-Pirard P, et al (2003). Involvement of mitochondria in acetaminophen-induced apoptosis and hepatic injury: roles of cytochrome c, Bax, Bid, and caspases. Toxicol Appl Pharmacol, 191, 118-29.

Goldstein J, Silberstein SD, Saper JR, et al (2005). Acetaminophen, aspirin, and caffeine versus sumatriptan succinate in the early treatment of migraine: results from the ASSET trial. Headache, 45, 973-82.

Gow PJ, Angus PW, Smallwood RA (1997). Transplantation in patients with paracetamol-induced fulminant hepatic failure. Lancet, 349, 651-2.

Gow PJ, Smallwood RA, Angus PW (1999). Paracetamol overdose in a liver transplantation centre: an 8-year experience. J Gastroenterol Hepatol, 14, 817-21.

Grivennikov SI, Greten FR, Karin M (2010). Immunity, inflammation, and cancer. Cell, 140, 883-99.

Harman AW, Fischer LJ (1983). Hamster hepatocytes in culture as a model for acetaminophen toxicity studies with inhibitors of drug metabolism. Toxicol Appl Pharmacol, 71, 330-41.

Hinson JA, Pohl LR, Monks TJ, et al (1981). Acetaminopheninduced hepatotoxicity. Life Sci, 29, 107-16.

Hinson JA, Roberts DW, James LP (2010). Mechanisms of acetaminophen-induced liver necrosis. Handb Exp Pharmacol, 2010, 369-405.

Honjo S, Srivatanakul P, Sriplung H, et al (2005). Genetic and environmental determinants of risk for cholangiocarcinoma via Opisthorchis viverrini in a densely infested area in Nakhon Phanom, northeast Thailand. Int J Cancer, 117, 854-60.

IARC (2011). Opisthorchis viverrini and Clonorchis sinensis. IARC Monogr Eval Carcinog Risks Hum, 100, 347-76.

Ishak K, Baptista A, Bianchi L, et al (1995). Histological grading and staging of chronic hepatitis. J Hepatol, 22, 696-699.

James LP, Farrar HC, Sullivan JE, et al (2001a). Measurement of acetaminophen-protein adducts in children and adolescents with acetaminophen overdoses. J Clin Pharmacol, 41, 846-51.

James LP, Lamps LW, McCullough S, et al (2003a). Interleukin 6 and hepatocyte regeneration in acetaminophen toxicity in the mouse. Biochem Biophys Res Commun, 309, 857-63. 
James LP, McCullough SS, Lamps LW, et al (2003b). Effect of $\mathrm{N}$-acetylcysteine on acetaminophen toxicity in mice: relationship to reactive nitrogen and cytokine formation. Toxicol Sci, 75, 458-67.

James LP, Simpson PM, Farrar HC, et al (2004). Correlation of MCP1 with toxicity in acetaminophen overdose. $\mathrm{J} \mathrm{Ark} \mathrm{Med}$ Soc, 100, 424-5.

James LP, Wilson JT, Simar R, et al (2001b). Evaluation of occult acetaminophen hepatotoxicity in hospitalized children receiving acetaminophen. Pediatric Pharmacology Research Unit Network. Clin Pediatr (Phila), 40, 243-8.

Jeffery WH, Lafferty WE (1981). Acute renal failure after acetaminophen overdose: report of two cases. Am J Hosp Pharm, 38, 1355-8.

Jenkins W, Perone P, Walker K, et al (2011). Fibroblast response to lanthanoid metal ion stimulation: potential contribution to fibrotic tissue injury. Biol Trace Elem Res, 144, 621-35.

Juasook A, Boonmars T, Kaewkes S, et al (2012). Anti-inflammatory effect of prednisolone on the growth of human liver fluke in experimental opisthorchiasis. Parasitol Res, 110, 2271-9.

Juasook A, Boonmars T, Wu Z, et al (2013). Immunosuppressive prednisolone enhances early cholangiocarcinoma in Syrian hamsters with liver fluke infection and administration of N-nitrosodimethylamine. Pathol Oncol Res, 19, 55-62.

Kass GE, Macanas-Pirard P, Lee PC, et al (2003). The role of apoptosis in acetaminophen-induced injury. Ann N Y Acad Sci, 1010, 557-9.

Klein F (2007). Cystic fibrosis--examination of the role of allergic bronchopulmonary aspergillosis. Pneumologie, 61, 628 .

Knight TR, Fariss MW, Farhood A, et al (2003). Role of lipid peroxidation as a mechanism of liver injury after acetaminophen overdose in mice. Toxicol Sci, 76, 229-36.

Knight TR, Kurtz A, Bajt ML, et al (2001). Vascular and hepatocellular peroxynitrite formation during acetaminophen toxicity: role of mitochondrial oxidant stress. Toxicol Sci, 62, 212-20.

Kon K, Ikejima K, Okumura K, et al (2007). Role of apoptosis in acetaminophen hepatotoxicity. $J$ Gastroenterol Hepatol, 22, 49-52.

Larson LW, Gerbert DA, Herman LM, et al (2006). ACC/AHA 2005 guideline update: chronic heart failure in the adult. JAAPA, 19, 53-6.

Lee JY, Jung DW, Park HA, et al (2004). Effect of taurine on biliary excretion and metabolism of acetaminophen in male hamsters. Biol Pharm Bull, 27, 1792-6.

Lee WM (2004). Acetaminophen and the U.S. Acute Liver Failure Study Group: lowering the risks of hepatic failure. Hepatology, 40, 6-9.

Liccardi G, Cazzola M, De Giglio C, et al (2005). Safety of celecoxib in patients with adverse skin reactions to acetaminophen (paracetamol) and other non-steroidal anti-inflammatory drugs. J Investig Allergol Clin Immunol, 15, 249-53.

LoGuidice A, Boelsterli UA (2011). Acetaminophen overdoseinduced liver injury in mice is mediated by peroxynitrite independently of the cyclophilin D-regulated permeability transition. Hepatology, 54, 969-78.

Lupo S, Yodis LA, Mico BA, et al (1987). In vivo and in vitro hepatotoxicity and metabolism of acetaminophen in Syrian hamsters. Toxicology, 44, 229-39.

Madhu C, Gregus Z, Klaassen CD (1989). Biliary excretion of acetaminophen-glutathione as an index of toxic activation of acetaminophen: effect of chemicals that alter acetaminophen hepatotoxicity. J Pharmacol Exp Ther, 248, 1069-77.

Makin AJ, Williams R, Bernal W (1998). Acetaminophen
Acetaminophen Overdose Enhances Early Cholangiocarcinoma

toxicity in an urban county hospital. $N$ Engl J Med, $\mathbf{3 3 8}$, 544; author reply -5 .

Miller MG, Jollow DJ (1984). Effect of L-ascorbic acid on acetaminophen-induced hepatotoxicity and covalent binding in hamsters. Evidence that in vitro covalent binding differs from that in vivo. Drug Metab Dispos, 12, 271-9.

Miller MG, Jollow DJ (1987). Relationship between sulfotransferase activity and susceptibility to acetaminopheninduced liver necrosis in the hamster. Drug Metab Dispos, 15, 143-50.

Muerkoster S, Wegehenkel K, Arlt A, et al (2004). Tumor stroma interactions induce chemoresistance in pancreatic ductal carcinoma cells involving increased secretion and paracrine effects of nitric oxide and interleukin-1beta. Cancer Res, 64, 1331-7.

Nam TG, Nara SJ, Zagol-Ikapitte I, et al (2009). Pyridine and pyrimidine analogs of acetaminophen as inhibitors of lipid peroxidation and cyclooxygenase and lipoxygenase catalysis. Org Biomol Chem, 7, 5103-12.

Nelson SD (1990). Molecular mechanisms of the hepatotoxicity caused by acetaminophen. Semin Liver Dis, 10, 267-78.

Ostapowicz G, Fontana RJ, Schiodt FV, et al (2002). Results of a prospective study of acute liver failure at 17 tertiary care centers in the United States. Ann Intern Med, 137, 947-54.

Rashed MS, Myers TG, Nelson SD (1990). Hepatic protein arylation, glutathione depletion, and metabolite profiles of acetaminophen and a non-hepatotoxic regioisomer, 3'-hydroxyacetanilide, in the mouse. Drug Metab Dispos, 18, 765-70

Rosen GM, Singletary WV, Jr., Rauckman EJ, et al (1983). Acetaminophen hepatotoxicity. An alternative mechanism. Biochem Pharmacol, 32, 2053-9.

Rzucidlo SJ, Bounous DI, Jones DP, et al (2000). Acute acetaminophen toxicity in transgenic mice with elevated hepatic glutathione. Vet Hum Toxicol, 42, 146-50.

Saito O, Aoe T, Yamamoto T (2005). Analgesic effects of nonsteroidal antiinflammatory drugs, acetaminophen, and morphine in a mouse model of bone cancer pain. $J$ Anesth, 19, 218-24.

Sasaki M, Yoshida S, Hiraga K (1983). Additional effect of acetaminophen on the mutagenicity and clastogenicity of $\mathrm{N}$-methyl-N'-nitro-N-nitrosoguanidine in cultured Chinese hamster CHO-K1 cells. Mutat Res, 122, 367-72.

Savides MC, Oehme FW (1983). Acetaminophen and its toxicity. J Appl Toxicol, 3, 96-111.

Siracusa MC, Reece JJ, Urban JF, Jr., et al (2008). Dynamics of lung macrophage activation in response to helminth infection. J Leukoc Biol, 84, 1422-33.

Sithithaworn P, Haswell-Elkins M (2003). Epidemiology of Opisthorchis viverrini. Acta Trop, 88, 187-94.

Sood S, Howell J, Sundararajan V, et al (2013). Paracetamol overdose in Victoria remains a significant health-care burden. $J$ Gastroenterol Hepatol, 28, 1356-60.

Sriraj P, Aukkanimart R, Boonmars T, et al (2013a). Does a combination of opisthorchiasis and ethyl alcohol consumption enhance early cholangiofibrosis, the risk of cholangiocarcinoma?. Parasitol Res, 112, 2971-81.

Sriraj P, Aukkanimart R, Boonmars T, et al (2013b). Alcohol and alkalosis enhance excystation of Opisthorchis viverrini metacercariae. Parasitol Res, 112, 2397-402.

Sriraj P, Boonmars T, Aukkanimart R, et al (2016). A combination of liver fluke infection and traditional northeastern Thai foods associated with cholangiocarcinoma development. Parasitol Res, 115, 3843-52.

Sumioka I, Matsura T, Kai M, et al (2004). Potential roles of hepatic heat shock protein 25 and $70 \mathrm{i}$ in protection of mice against acetaminophen-induced liver injury. Life Sci, 74, 
2551-261.

Tirmenstein MA, Nelson SD (1990). Acetaminophen-induced oxidation of protein thiols. Contribution of impaired thiolmetabolizing enzymes and the breakdown of adenine nucleotides. $J$ Biol Chem, 265, 3059-65.

Widmann JJ, Fahimi HD (1975). Proliferation of mononuclear phagocytes (Kupffer cells) and endothelial cells in regenerating rat liver. A light and electron microscopic cytochemical study. Am J Pathol, 80, 349-66.

Yang R, Zou X, Koskinen ML, et al (2012). Ethyl pyruvate reduces liver injury at early phase but impairs regeneration at late phase in acetaminophen overdose. Crit Care, 16, R9.

This work is licensed under a Creative Commons AttributionNon Commercial 4.0 International License. 